\title{
Produksi, komposisi botani dan kapasitas tampung padang penggembalaan alam Kecamatan Haharu Kabupaten Sumba Timur
}

\section{Production, Botanical Composition, and Carrying Capacity of Pasture in Haharu District East Sumba Regency}

\author{
Marselinus Hambakodu \\ Program Studi Peternakan, Fakultas Sains dan Teknologi, Universitas Kristen Wira \\ Wacana Sumba \\ JI. R. Soeprato, No. 35, Prailiu, Waingapu, Sumba Timur, NTT, Kode Pos 87113 \\ *Email Koresponden: marsel.hambakodu@unkriswina.ac.id
}

\begin{abstract}
Abstrak. Padang penggembalaan perlu didata dan dikelola karena sebagai sumber pakan yang murah dan mudah diperoleh untuk dikonsumsi ternak. Tujuan penelitian untuk mengetahui produksi, komposisi botani dan kapasitas tampung di Kecamatan Haharu Kabupaten Sumba Timur. Penelitian ini telah dilaksanakan di padang penggembalaan alam Kecamatan Haharu, Kabupaten Sumba Timur. Penelitian dilaksanakan pada bulan Juni sampai Agustus 2021. Metode yang digunakan dalam penelitian adalah metode survei dan pengukuran serta pengamatan langsung di lapangan. Pengukuran produksi hijauan menggunakan metode "Actual Weight Estimate" dengan menggunakan kuadran ukur $1 \mathrm{~m} \times 1 \mathrm{~m}$. Data yang diperoleh ditabulasi dan dihitung untuk mendapatkan total produksi hijauan pakan, komposisi botani, dan kapasitas tampung. Hasil penelitian menunjukkan bahwa padang penggembalaan Kecamatan Haharu memiliki produksi bahan segar sebesar $2.109,512 \mathrm{~kg} / \mathrm{ha}$, produksi bahan kering sebesar $1.304,754 \mathrm{~kg} / \mathrm{ha}$, nilai Summed Dominance Ratio (SDR) rumput $98,74 \%$, legum $1,08 \%$, dan gulma $0,17 \%$. Padang penggembalaan ini juga memiliki kapasisitas tampung sebesar $0,03 \mathrm{ST} / \mathrm{ha}$ /tahun. Kesimpulan, padang padang penggembalaan alam di Kecamatan Haharu didominasi oleh rumput alam dengan kapasitas tampung yang rendah pada musim kemarau.
\end{abstract}

Kata kunci: komposisi botani, kapasitas tampung, padang penggembalaan alam.

\begin{abstract}
Pasture area must be managed and record existing condition doe to as source cheapest feed and easy to find out for livestock consumption. This experiment was conducted to analyze the production, botanical composition, and carrying capacity of pasture in the Haharu District, East Sumba Regency. The experiment was conducted from June to August 2021, using the field survey method. The experiment was carried out in Haharu district, East Sumba regency. Forage production measured by actual weight estimate method with $1 \mathrm{~m} \times 1 \mathrm{~m}$ of the frame as tool utilization. Data was collected then analyzed to find out production, botanical composition, and carrying capacity of forage in the pasture. Statistical analysis showed that the value of Summed Dominance Ratio (SDR) was $98,74 \%$ grass, 1,08 \% legumes, and 0,17\% weeds. Fresh production was $2.109,512 \mathrm{~kg} / \mathrm{ha}$ and dry matter production was $1.304,754 \mathrm{~kg} / \mathrm{ha}$ with a carrying capacity was 0,03 AU/ha/year. In conclusion, the pasture area in Haharu district was dominated by grass, and carrying capacity was low at dry season.
\end{abstract}

Keywords: botanical composition, carrying capacity, pasture. 
Hambakodu

ANIMPRO: Conference of Applied Animal Science Proceeding Series

\section{PENDAHULUAN}

Padang penggembalaan di Indonesia memiliki prospek dalam pembangunan peternakan. Provinsi Nusa Tenggara Timur pada umumnya dan pulau Sumba pada khsusunya merupakan daerah yang sangat potensial bagi pengembangan ternak ruminansia seperti sapi, kerbau, kambing dan domba. Provinsi Nusa Tenggara Timur memiliki sumber daya pakan berupa padang penggembalaan dengan luas 832.228 ha, produksi hijauan 1.884 .996 ton BK, kapasitas tampung 918.279 ekor (BPS, 2020). Luas padang penggembalaan pulau Sumba adalah 227.020 ha terdiri dari empat Kabupaten yaitu Kabupaten Sumba Timur seluas 221.371 ha, Kabupaten Sumba Barat seluas 8.245 ha; Kabupaten Sumba Tengah seluas 37.696 ha, dan Kabupaten Sumba Barat Daya seluas 9.708 ha (BPS, 2020). Kabupaten Sumba Timur memiliki luas padang penggembalaan paling luas dari empat Kabupaten yang ada di Pulau Sumba. Kabupaten Sumba Timur merupakan salah satu daerah sentral pengembangan peternakan yakni di Kecamatan Pandawai. Kabupaten Sumba Timur memiliki luas wilayah daratan $7.000,50$ ha yang tersebar pada satu pulau utama dan 3 pulau kecil yakni pulau Salura, pulau Mengkudu dan Pulau Nuha yang tidak berpenghuni (BPS, 2020).

Kecamatan Haharu merupakan salah satu kecamatan yang memiliki padang penggembalaan alam yang luas dan populasi ternak terbanyak di kabupaten Sumba Timur. Jumlah populasi ternak sapi 2.402 ekor, kerbau 482 ekor, kambing dan domba 3.060 ekor, kuda 1.653 ekor dengan luas wilayah \pm 60.150 ha (BPS, 2020). Lokasi ini belum pernah diteliti khususnya produksi bahan segar dan komposisi botani serta kapasitas tampung padahal jumlah ternak ruminansia yang merumput disini cukup banyak. Produksi hijauan di padang penggembalaan merupakan jumlah hijauan pakan yang dihasilkan oleh padang penggembalaan dalam bentuk bahan segar dan bahan kering. Komposisi botani juga menjadi penting yaitu angka yang digunakan untuk menilai kualitas padang penggembalaan yang dapat mempengaruhi aktivitas ternak, sedangkan kapasitas tampung untuk mengetahui kemampuan padang penggembalaan untuk menghasilkan hijauan makanan ternak yang dibutuhkan oleh sejumlah ternak yang digembalakan dalam satuan luasan tertentu atau kemampuan padang penggembalaan untuk menampung ternak per hektar. Padang penggembalaan pada awal musim kemarau lebih didominasi rumput alam seperti Heteropogon insignis, Bracharia decumbens dan Bothriochloa ischaemum dan kapasitas tampung 1,001 ST/ha/tahun (Hae et al., 2020). Nilai nutrisi dan kecernaan hijauan di padang penggembalaan Kecamatan Haharu cukup rendah dengan PK 34\%, SK 41-59\% (Hambakodu et al., 2021) serta kecernaan BK 30-35\%, kecernaan BO 28-32\% (Hambakodu, 2021), sehingga perlu ada kajian lebih lanjut tentang produksi, komposisi botani dan kapasitas tampung pada padang penggembalaan di lokasi kecamatan Haharu. Penelitian ini bertujuan untuk mengetahui produksi, komposisi botani, kapasitas tampung padang penggembalaan Kecamatan Haharu Kabupaten Sumba Timur.

\section{MATERI DAN METODE}

\section{Lokasi dan Waktu Penelitian}

Penelitian ini telah dilaksanakan di Kecamatan Haharu Kabupaten Sumba Timur pada tanggal 01 Juni - 01 Agustus 2021.

\section{Metode Pengambilan Data}

Data yang diambil dalam penelitian ini adalah data primer dan data sekunder. Data primer diperoleh dari hasil pengukuran langsung di lapangan sedangkan data sekunder bersumber dari literatur dan instansi terkait. Jenis data primer yang diambil adalah produksi hijauan pakan dan komposisi botani, dan jenis ternak yang digembalakan sedangkan data sekunder diambil meliputi kondisi geografis, luas padang penggembalaan, ketinggian tempat penelitian dari permukaan laut (DPL), tata guna lahan (landuse).

\section{Materi dan Alat-alat Penelitian}

Materi penelitian adalah hijauan rumput dan legum dan gulma yang tumbuh di atas areal padang penggembalaan alam di lokasi penelitian dan alat-alat yang digunakan berupa bingkai kuadran 1 
$\mathrm{m} \times 1 \mathrm{~m}$, sabit, gunting, kantong plastik, timbangan duduk kapasitas 5-10 kg, kalkulator, camera, buku panduan identifikasi jenis rumput, legum dan gulma, alat tulis-menulis, dan GPS (Global Position System ) sebagai alat yang digunakan untuk mengukur luas padang dan untuk mengetahui ketinggian lokasi penelitian dari permukaan laut.

\section{Variabel Penelitian}

A. Produksi Hijauan makanan ternak.

Untuk mengukur hijauan makanan ternak, rata-rata produksi hijauan makanan ternak dihitung menggunakan rumus: $\bar{X}=\frac{\sum x i}{n}$

Dimana :

$\sum x i$ : jumlah produksi pada setiap pengamatan $(i=1,2,3, \ldots, n)$

$\bar{X}$ : rata-rata produksi yang ada

$\mathrm{n}$ : jumlah pengamatan ( 80 )

B. Komposisi botani

Untuk memperoleh gambaran secara detail jenis vegetasi, dan persebaran jenis yang ada pada padang rumput. Kelimpahan jenis ditentukan berdasarkan.

Kerapatan mutlak : Jumlah individu suatu spesies dalam suatu plot pengamatan

Kerapatan nisbi : ( $\Sigma$ total individu suatu jenis : $\sum$ individu seluruh jenis) $\times 100 \%$

Frekuensi mutlak : Jumlah sampling plot yang ditempati oleh suatu jenis tertentu

Frekuensi nisbi : ( $\Sigma$ total frekuensi suatu jenis : $\sum$ nilai frekuensi seluruh jenis) $\times 100 \%$

Menghitung nilai penting setiap jenis di dalam komunitas pengamatan dengan menggunakan rumus menurut Tjitrosoedirdjo, S. dkk (1984) :

\section{Summed Dominance Ratio $(S D R)=\left(K_{n}+F_{n}\right) / 2$}

Identifikasi spesies rumput, legum dan gulma

Untuk mengetahui vegetasi rumput lapangan maka dilakukan identifikasi spesies rumput dengan cara mengamati rumput yang ada di padang, kemudian diambil untuk dicocokan di buku identifikasi rumput lapangan.

C. Kapasitas Tampung (Reksohadiprodjo, 1985)

Untuk mengukur kapasitas tampung ternak pada suatu areal padang penggembalaan dihitung menggunakan rumus voisin: $(y-1) s=r$

Dimana :

y : Perbandingan luas lahan yang dibutuhkan 1 ekor sapi per tahun dibandingkan per bulan

$s$ : stay/ periode merumput

$r:$ rest/ periode istirahat

\section{Prosedur Penelitian}

Prosedur Pengambilan Data untuk Produksi Hijauan Makanan Ternak

Metode yang digunakan dalam pengambilan data produksi hijauan pakan adalah metode survei serta pengukuran dan pengamatan langsung di lapangan. Pengukuran produksi hijauan dilakukan dengan menggunakan metode "Actual Weight Estimate", Susetyo (1980) yaitu dengan menggunakan petak ukur $1 \mathrm{~m} \times 1 \mathrm{~m}$. Penempatan petak ukur pada padang rumput dilakukan secara acak sistematis, setelah itu dilakukan pemotongan vegetasi kemudian dimasukkan ke dalam kantong plastik untuk segera ditimbang.

\section{Prosedur Pengambilan Data untuk Komposisi Botani}

Metode yang digunakan dalam pengambilan data komposisi botani yaitu metode pengukuran secara langsung yang dibagi beberapa metode, diantaranya dengan metode pengukuran Summed Dominance Ratio (SDR) berdasarkan frekuensi (keseringan), density (kepadatan).

Prosedur kerjanya sebagai berikut :

a. Melakukan survei pendahuluan guna memahami bentuk dan zona lingkungan lahan pengamatan. 
b. Menggunakan bingkai kuadran untuk pengambilan sampling plot. Bingkai kuadran yang digunakan berukuran $1 \mathrm{~m} \times 1 \mathrm{~m}$.

c. Melakukan pelemparan bingkai kuadran secara acak pada daerah pengamatan dengan tujuan untuk penentuan titik awal atau titik pusat.

d. Pada daerah pengamatan dilakukan penempatan plot pertama untuk titik awal dilakukan pelemparan, dari titik awal tersebut penempatan plot pertama keempat arah mata angin Timur, Barat, Utara, Selatan dengan metode yang sama dan masing-masing arah sebanyak 20 plot.

e. Melakukan observasi jenis vegetasi, dan penyebaran jenis yang ada pada setiap plot dan menentukan besar frekuensi, kerapatan dan dominansi setiap jenis dengan cara menghitung setiap vegetasi yang ada dalam setiap plot pengamatan.

f. Identifikasi jenis atau spesies hijauan makanan ternak.

\section{Analisis Data}

Semua data primer yang diperoleh ditabulasi dan dihitung untuk mendapatkan persentase produksi hijauan pakan dan komposisi botani serta kapasitas tampung. Data dianalisis menggunakan metode deskriptif.

\section{HASIL DAN PEMBAHASAN}

\section{Produksi Hijauan}

Produksi hijauan pakan adalah jumlah hijauan yang dihasilkan di padang penggembalaan selama periode tertentu dalam bentuk bahan segar dan bahan kering. Produksi bahan segar dan bahan kering padang penggembalaan kecamatan Haharu dapat dilihat pada Tabel 1.

Tabel 1. Rerata Produksi Hijauan padang pengembalaan di Kecamatan Haharu

\begin{tabular}{ccc}
\hline Komposisi Botani & Produksi Hijauan Segar & Produksi Bahan Kering \\
\hline Rumput & $1.872,072 \mathrm{Kg} / \mathrm{Ha}$ & $1.157,89 \mathrm{Kg} / \mathrm{Ha}$ \\
Legum & $237,44 \mathrm{~kg} / \mathrm{Ha}$ & $146,864 \mathrm{~kg} / \mathrm{Ha}$ \\
Gulma & $56,97 \mathrm{Kg} / \mathrm{Ha}$ & $35,24 \mathrm{~kg} / \mathrm{ha}$ \\
\hline Total & $2.166,5 \mathrm{~kg} / \mathrm{Ha}$ & $1.339,99 \mathrm{~kg} / \mathrm{ha}$ \\
\hline
\end{tabular}

Hasil penelitian pada Tabel 1 menunjukkan bahwa produksi bahan segar hijauan pakan pada awal musim kemarau di kecamatan Haharu yaitu 2.166,5 $\mathrm{kg} \mathrm{kg}$ atau 2,1 ton/ha, sedangkan produksi bahan kering 1.339,99 $\mathrm{kg} / \mathrm{ha}$ atau 1,3 ton/ha. Angka ini cukup rendah dibandingkan dengan produksi hijauan pakan di padang penggembalaan Desa Maubokul Kecamatan Padawai Kabupaten Sumba Timur yakni 1.866,8 kg/ha atau 1,8 ton/ha (Hae et al., 2020). Faktor yang mempengaruhi tinggi rendah produksi rumput di padang penggembalaan yakni ketersediaan air, curah hujan, suhu, kelembaban, struktur dan topografi tanah. Produksi hijauan di padang penggembalaan dipengaruhi oleh ketersediaan air (Yasin, 2013). Faktor lain jug dipengaruhi oleh pergantian musim hujan dan musim kemarau (Manu, 2007), serta faktor topografi tanah yang berbukit dan berbatu akan berpengaruh pada pertumbuhan hijauan di padang penggembalaan alam (Hambakodu et al., 2021).

\section{Komposisi Botani}

Komposisi botani adalah angka yang digunakan untuk menentukan penilaian secara kualitatif padang penggembalaan alam yang mempengaruhi aktivitas ternak (Selan et al., 2019). Nilai Summed Dominance Ratio (SDR) padang penggembalaan alam kecamatan Haharu dapat dilihat pada Tabel 2. 
Hambakodu

ANIMPRO: Conference of Applied Animal Science Proceeding Series

Tabel 2. Komposisi botani dan nilai SDR padang pengembalaan di Kecamatan Haharu

\begin{tabular}{ccccccc}
\hline NO & Spesies/jenis & $\sum \mathrm{Km}$ & $\sum \mathrm{Kn}$ & $\mathrm{Fm} \%$ & $\mathrm{Fn} \%$ & SDR \% \\
\hline 1 & Rumput & 80.263 & 98,74 & 320 & 70,07 & 86,41 \\
2 & Legum & 881 & 1,08 & 90 & 20,83 & 10,96 \\
3 & Gulma & 141 & 0,17 & 22 & 5,09 & 2,63 \\
\hline Total & & 81.285 & 100 & 432 & 100 & 100 \\
spesies & & & & & & \\
\hline
\end{tabular}

Hasil penelitian pada Tabel 2 menggambarkan jumlah kerapatan mutlak (Km) rumput 80.263 dan leguminosa 881, gulma 141 sedangkan nilai frekuensi mutlak (Fm) rumput 320 dan leguminosa 90, dan gulma 22. Kerapatan dalam setiap plot cukup padat dan penyebarannya merata karena hampir semua datap ditumbuhi oleh berbagai jenis hijauan. Nilai frekuensi nisbi (Fn) rumput 70,07\% dan leguminosa $20,83 \%$, dan gulma 5,09\%, sedangkan nilai Summed Dominance Ratio (SDR) dari rumput $86,41 \%$ dan leguminosa $10,96 \%$, dan gulma 2,63 \%. Padang penggembalaan alam di kecamatan Haharu didominasi oleh rumput alam dan diikuti oleh leguminosa dan gulma. Kondisi ini menunjukkan bahwa padang penggembalaan di kecamatan Haharu tidak ideal, karena padang penggembalaan yang ideal terdiri dari rumput dan legum adalah $60 \%: 40 \%$. Kondisi ini dipengaruhi oleh kondisi lokasi penelitian berada di dekat pesisir pantai utara Pulau Sumba. Pertumbuhan legume sangat minim disebabkan oleh kodisi tanah bersifat alkalis sehingga legume sulit untuk bertumbuh (Manu, 2007), sedangkan pertumbuhan rumput lebih tinggi daripada legum karena ada unsur hara $\mathrm{N}$ tahan di padang penggembalaan alam yang merangsang akar untuk tumbuhan rumput dan mengurangi jumlah legum (Selan et al., 2019). Padang penggembalaan ditumbuhi beranekaragam hijauan, hal ini sesuai pendapat (Yoku et al., 2015) menyatakan bahwa keanekaragaman hijauan yang tumbuh pada suatu padang penggembalaan dipengaruhi oleh musim. Menurut Sanderson et al. (2015) bahwa komposisi botani juga dipengaruhi oleh jenis rumput yang tumbuh di padang penggembalaan alam.

\section{Kapasitas Tampung}

Kapasitas tampung adalah kemampuan suatu padang penggembalaan untuk menghasilkan hijauan pakan yang dibutuhkan oleh sejumlah ekor ternak yang digembalakan dalam luasan satu hektar. Berdasarkan hasil penelitian kapasitas tampung padang penggembalaan alam di kecamatan Haharu jika menggunakan asumsi 40\% proper use factor (FUP) dengan 1 UT (Indonseia) sama dengan setara dengan 1 ekor sapi dewasa yang berbobot rata-rata $235 \mathrm{~kg}$ (Suhubdy, 2018) maka dihasilkan kapasitas tampung sebesar 0,03 UT/ha/tahun. Kapasitas tampung ini lebih rendah dibandingkan hasil penelitian (Sulfiar et al., 2020) sebesar 0,05 UT/ha/tahun, dan (Hae et al., 2020) sebesar 1,001 UT/ha/tahun. Padang penggembalaan yang baik biasanya mampu menampung sebanyak 2,5 ST/ha/th (Hawolambani et al., 2015), bahkan lebih sebesar 5,8 UT/ha/tahun (Habaora et al., 2020). Berdasarkan hasil diatas maka dapat dikatakan bahwa kapasitas tampung dari padang penggembalaan tersebut sebesar 0,03 UT/Ha dan padang penggembalaan tersebut kurang baik karna nilai Unit ternak per hektar rendah. Semakin rendah UT/Ha maka semakin kurang baik padang penggembalaan, sedangkan semakin tinggi nilai UT/ha maka semakin baik padang penggembalaan. Kapasitas tampung terendah kisaran 0,01 - 0,09 UT/ha, sedangkan nilai tertinggi lebih dari 1,0 UT/ha. Faktor yang mempengaruhi kapasitas tampung padang penggembalaan adalah produksi hijauan per satuan luas lahan, dimana produksi hijauan per satuan luas lahan di kecamatan Haharu cukup rendah. Menurut (Hae et al., 2020) bahwa Semakin besar tingkat produksi hijauan per satuan luas lahan, maka akan semakin tinggi pula kemampuannya untuk menampung sejumlah ternak. Selain itu faktor topografi lahan turut mempengaruhi kapasitas tampung (Habaora et al., 2020) yakni jika kemiringan lereng $30-60 \%$, maka kapasitas penggembalaan menuruan hingga $60 \%$, sedangkan jika kemiringan lereng $>60 \%$ kapasitas penggembalaan turun hingga $100 \%$.

\section{KESIMPULAN}


Padang penggembalaan alam Kecamatan Haharu Kabupaten Sumba Timur memiliki produksi bahan kering hijauan sebesar $1.339,99 \mathrm{~kg} / \mathrm{ha}$ atau 1,3 ton/ha dengan kapasitas tampung 0,03 $\mathrm{UT} / \mathrm{Ha} / \mathrm{Tahun}$. Komposisi botani lebih didominasi oleh rumput $86,41 \%$ dan leguminosa $10,96 \%$ dan gulma $2,63 \%$.

\section{DAFTAR PUSTAKA}

BPS. (2020). Sumba Timur in Figures 2020. In BPS-Statistics Of Sumba Timur (pp. 141-144).

Habaora, F., Fuah, A., Abdullah, L., Priyanto, R., Yani, A., \& Purwanto, B. (2020). Botanical Composition and Carrying Capacity in Various Agroecosystems on The Timor Island. Jurnal Ilmu Produksi Dan Teknologi Hasil Peternakan, 08(2), 72-79.

Hae, V. H., Kleden, M. M., \& Temu, S. T. (2020). Production, Botanical Composition and Carrying Capacity Of Forage in Native Grassland at Early Dry Season. Jurnal Nukleus Peternakan, 7(1), 14-22. http://ejurnal.undana.ac.id/nukleus/article/view/2299

Hambakodu, M. (2021). Evaluation of Nutritional Value and In Vitro Digestibility of Natural Grass on Plantation Land and Pasture. Jurnal Peternakan Indonesia, 23(2), 130-135. https://doi.org/10.25077/jpi.23.2.130-135.2021

Hambakodu, M., Pawulung, J. P., Nara, M. C., Amah, U. A. R., Ranja, E. P., \& Tarapanjang, A. H. (2021). Identifikasi Hijauan Makanan Ternak di Lahan Pertanian dan Padang Penggembalaan Kecamatan Haharu Kabupaten Sumba Timur. Jurnal IImu Dan Teknologi Peternakan Tropis, 8(1), 43-50. https://doi.org/10.33772/jitro.v8i1.14601

Hawolambani, Y., Nastiti, H., \& Manggol, Y. (2015). Produksi Hijauan Makanan Ternak dan Komposisi Botanipadang Penggembalaan Alam Pada Musim Hujan di Kecamatan Amarasi Barat Kabupaten Kupang. Jurnal Nukleus Peternakan (Juni, 2(1), 59-65.

Manu, A. (2007). Productivity of West Timor Sabana Sabana. Pastura: Journal of Tropical Forage Science, 3(1), 25-29.

Reksohadiprodjo S. 1985. Produksi Tanaman Hijauan Makanan Ternak Tropik. BPFE. Yogyakarta.

Sanderson, M. A., Stout, R., \& Brink, G. (2015). Productivity, Botanical Composition, and Nutritive Value of Commercial Pasture Mixtures. Agronomy Journal, 108(1), 93-100. https://doi.org/10.2134/agronj15.0259

Selan, A. D., Manggol, Y. H., \& Temu, S. T. (2019). Botany Compostion, Forage Prodcution And Carry Capacity of Natural Pasture In Desa Bena Kecamatan Amanuban Selatan Kabupaten Timor Tengah Selatan. Jurnal Peternakan Lahan Kering, 1(1), 136-142.

Sulfiar, A., Atmoko, B., Guntoro, B., \& Budisatria, I. (2020). Study of Pasture Productivity for Semi-Intensive Cattle System during Dry Season in the South Konawe Regency, Southeast Sulawesi. Bulletin of Animal Science, 44(3), 85-91. https://doi.org/10.21059/buletinpeternak.v44i3.52742

Susetyo S. 1980. Padang Penggembalaan. Departemen Ilmu Makanan Ternak. Fakultas Peternakan, IPB. Bogor.

Yasin, S. (2013). Ruminant Eating Behavior as a Bioindicator of Phenology and Sheadline Dynamics Grazing Land. Pastura: Journal of Tropical Forage Science, 3(1), 1-4. https://doi.org/https://doi.org/10.24843/Pastura.2013.v03.i01.p01

Yoku, O., Supriyantono, A., Widayati, T., \& Sumpe, I. (2015). Botanical Composition and Distribution of Local Forage Species Natural Pastures in West Papua. Pastura: Journal of Tropical Forage Science, 4(2), 62-65. https://doi.org/10.24843/Pastura.2015.v04.i02.p02 